\title{
Gerontology
}

\section{Blood-Based Therapies to Combat Aging}

\author{
Joseph M. Castellano \\ Department of Neuroscience, Department of Neurology, Friedman Brain Institute, Ronald M. Loeb Center for \\ Alzheimer's Disease, Icahn School of Medicine at Mount Sinai, New York, NY, USA
}

\section{Keywords}

Young blood - Young plasma - Parabiosis · Aging ·

Alzheimer's disease - Neurodegenerative disease - GDF11 . TIMP2 Osteocalcin

\section{Abstract}

Dysfunction associated with the aging process positions aging as a leading culprit for development of devastating diseases and mounting health-care costs. Many age-associated conditions for which aging increases risk are neurological disorders with no effective treatments, including Alzheimer's disease. As the proportion of aged individuals continues to rise in the coming decades, aging-related costs are expected to increase dramatically. Diverse approaches have emerged to meet the clinical need to treat aging and its associated conditions, including those aimed at increasing longevity, slowing the aging process itself, and improving healthspan. An emerging approach takes advantage of molecules circulating in the blood to limit or reverse aspects of aging in various organs throughout the body. Efforts are underway to translate these findings into novel therapeutics that harness the activity of youth-associated molecules present within blood. Here, we discuss the current state of blood- based approaches in this arena. Despite the apparent ease with which blood products might conceivably be applied as treatment paradigms, we propose that challenges nonetheless exist, which may be overcome with mechanistic studies that identify common pathways for targeted therapeutics.

(c) 2018 S. Karger AG, Basel

\section{Introduction}

Much of the global population has enjoyed increased lifespan in the era of modern medicine, yet this has come at the cost of increased social and economic burden as our societies struggle to cope with the toll of aging-associated conditions. Leading causes of mortality in developed countries include conditions for which aging is a powerful risk factor, including cancer, diseases of the cardiovascular system, and various neurological disorders. Strikingly, for many of the aging-associated neurological disorders, including Alzheimer's disease (AD), there are no effective treatments despite robust research and clinical investment for several decades. Delaying the onset of $\mathrm{AD}$ by only a modest number of years would translate into meaningful benefits for affected individuals in terms of

\section{KARGER}

(C) 2018 S. Karger AG, Basel

E-Mail karger@karger.com

www.karger.com/ger
Joseph M. Castellano

Department of Neuroscience, Department of Neurology, Friedman Brain Institute Ronald M. Loeb Center for Alzheimer's Disease, Icahn School of Medicine at

Mount Sinai, 1425 Madison Ave, Box 1065, New York, NY 10029 (USA)

E-Mail joseph.castellano@mssm.edu 
quality of life. Along these lines, a novel approach within geroscience research has been to delay the onset of aging to mitigate the burden of aging-associated conditions by targeting one's healthspan - the length of time spent as a healthy individual [1]. In principle, this approach is not necessarily based on catering therapies to specific diseases, but rather on treating the umbrella of aging-associated disorders to increase healthspan while maximizing the ratio of health benefit and investment [2]. Thought leaders within the geroscience community have argued for the re-classification of "aging" and its associated conditions as a disease in the hope of stimulating approval and investment. Metformin, an FDA-approved drug for the treatment of diabetes, is being tested in a cohort of elderly individuals as a proof-of-concept trial known as the Targeting Aging with Metformin (TAME) trial that may serve to convince the FDA that aging should be classified as a disease worthy of dedicated therapies. Aside from metformin, various other anti-aging directions are being actively evaluated, including rapamycin (and "rapalogs") and NAD+ [2], and diet-based approaches that include variants of the Mediterranean diet, a "fasting-mimicking" diet, and caloric restriction $[3,4]$.

The disease-associated consequences of aging will require innovative therapeutic approaches grounded in understanding and harnessing the complex physiology of diverse organ systems. The discovery that the systemic environment can be exploited to alter regenerative capacity in various aged tissues represents one such approach, a research topic that has ignited both scientific and public interest. A flurry of studies has demonstrated that exposure to young blood improves the function of various aged tissues, including skeletal muscle, liver, and brain (see $[5,6]$ for review). Still other studies have described the activity of specific youth-associated proteins that partially recapitulate the anti-aging activity of young blood, including GDF11 [7-9], TIMP2 [10], oxytocin [11], and osteocalcin [12]. Most recently, we have reported similar activity present within human blood plasma transferred to aged mice, which results in enhanced synaptic plasticity in memory-relevant brain regions and corresponding improvements in cognitive function [10]. The current cache of studies argues that development of blood-based therapies is a prudent strategy for limiting aging-associated dysfunction. We discuss key findings in this field and describe various approaches being implemented towards translation of these findings. Finally, conceptual, practical, and ethical challenges to the realization of bloodbased regenerative medicine will be discussed. We suggest that further mechanistic studies are needed to iden- tify common pathways, thus facilitating the development of drugs that minimize off-target effects while maximizing the revitalizing potential of blood products and their derivatives.

\section{Anti-Aging Approaches to Exploit the Systemic Environment}

Early studies probing the systemic influence on aging and lifespan utilized a parabiosis model in which aged rats were surgically connected to young to uncover evidence suggestive of young blood's influence on lifespan in aged animals $[13,14]$. More recent work has taken advantage of the observations made by the Rando laboratory that investigated the link between the systemic environment and rejuvenation of aged tissue. In this seminal work, aged mice were surgically connected to young mice using a refined version of the classical parabiosis technique [15]. The young blood-exposed aged partner in "heterochronic" pairs experiences youthful levels of skeletal muscle regeneration in an injury model compared to isochronic pairs of aged mice [15]. A subsequent study demonstrated reduced age-related muscle fibrosis with increased Wnt signaling following young blood exposure [16]. Later studies also reported the skeletal muscle stem cell regeneration phenotype using either heterochronic parabiosis [9] or a blood exchange model [17]. Despite the complexity of the model [18], parabiosis has proven to be an invaluable research tool in expanding the role of young blood in aging across many tissues [5]. Loffredo et al. [8] reported that aged mice sharing young blood via parabiosis exhibit reduced age-related cardiac hypertrophy and decreased ventricular myocyte size. Age-related decreases in pancreatic $\beta$-cell proliferation are reverted towards youthful levels after only 2-3 weeks of sharing young blood [19], and parameters of kidney aging are also improved in aged parabionts sharing young blood [20]. The rejuvenating potential of young blood was also illustrated in a model of tibial fracture repair; bone healing in aged mice is significantly improved when sharing young blood [21]. Perhaps most surprisingly, the effects of young blood are transduced - via largely unknown mechanisms - beyond the blood-brain barrier to ameliorate age-related brain dysfunction. Aged parabionts exposed to young blood exhibit increased adult neurogenesis $[7,22]$ and improved hippocampal synaptic plasticity [23]. Furthermore, in a toxin-induced model of focal demyelination in the aged mouse spinal cord, exposure to young blood via parabiosis increases remyelination at the injury site [24]. 
Several studies have assessed the rejuvenating potential of young plasma, the soluble component of blood, finding that it recapitulates many of the phenotypes conferred by young blood in parabiosis studies. For example, intravenous injections in aged mice with young mouse plasma increase expression of hippocampal synaptic plasticity markers and long-term potentiation, memory, and anxiety-related behavior [12, 23]. Aged rats treated with young plasma exhibit improvements in liver regeneration and other parameters associated with liver aging, partially through alterations in autophagy [25]. Systemic treatment of aged immunodeficient ("NSG") mice with human umbilical cord plasma was found to similarly improve measures of hippocampal synaptic plasticity and cognitive performance [10], suggesting that plasma possesses rejuvenating activity regardless of species. Finally, mice engineered to develop the amyloid lesions found in AD patients exhibit improved synaptic integrity when exposed to young blood or plasma [26] and may exhibit reduced amyloid burden in a separate model [27]. Moreover, a recent study reported enhanced non-amyloidogenic activity within umbilical cord serum that improves $\mathrm{AD}$-like pathology and cognitive performance in mice [28].

These early heterochronic parabiosis and plasma transfer studies motivated the approach to simply transfuse blood products from young individuals to elderly subjects suffering from age-related diseases. Alkahest, a Grifols-backed start-up focused on translating bloodbased approaches for the treatment of age-related conditions, sponsored a preliminary trial conducted by Stanford University that assessed young blood plasma. This trial, the Plasma for Alzheimer's Symptom Amelioration (PLASMA) study [29], evaluated the feasibility and safety of treating mild to moderate $\mathrm{AD}$ subjects with plasma from young adults (18-30 years of age). Nine subjects received plasma or placebo control weekly over the course of 1 month prior to switching to the opposite treatment; an additional 9 subjects were treated using an open-label amendment protocol. In general, the treatment was well tolerated, and no treatment-related adverse events were reported. The study authors also reported hints of improvement in secondary outcomes of functional activity gleaned from clinical assessments. A subsequent Phase 2 trial is focused on a related approach to treat subjects with a proprietary fraction-refined product, GRF6019. Reducing the complexity of conventional blood plasma products in this way presumably creates a more efficacious product that is better equipped to target age-related phenotypes.
Table 1. Anti-aging or pro-aging effects of reported blood-borne proteins

\begin{tabular}{|c|c|c|c|}
\hline $\begin{array}{l}\text { Blood-borne } \\
\text { protein }\end{array}$ & $\begin{array}{l}\text { Anti- or } \\
\text { pro-aging? }\end{array}$ & Reported effects & References \\
\hline GHRH & anti-aging & $\begin{array}{l}\uparrow \text { memory/cognitive } \\
\text { function }\end{array}$ & 36,37 \\
\hline CCL11 & pro-aging & $\begin{array}{l}\downarrow \text { neurogenesis, } \\
\downarrow \text { memory }\end{array}$ & 22 \\
\hline $\mathrm{B} 2 \mathrm{M}$ & pro-aging & $\begin{array}{l}\downarrow \text { neurogenesis, } \\
\downarrow \text { memory }\end{array}$ & 22,31 \\
\hline GDF11 & anti-aging & $\begin{array}{l}\downarrow \text { cardiac hypertrophy, } \\
\uparrow \text { muscle regeneration, } \\
\uparrow \text { neurogenesis, } \\
\uparrow \text { neurovasculature }\end{array}$ & $7,8,9$ \\
\hline Oxytocin & anti-aging & $\uparrow$ muscle regeneration & 11 \\
\hline TIMP2 & anti-aging & $\begin{array}{l}\uparrow \text { synaptic plasticity, } \\
\uparrow \text { memory }\end{array}$ & 10 \\
\hline Osteocalcin & anti-aging & $\downarrow$ anxiety, $\uparrow$ memory & 12 \\
\hline
\end{tabular}

Several groups have also examined factors present in aged blood that may play a role in the development of agerelated phenotypes. One study reported that young mice sharing aged blood exhibit impaired hippocampal neurogenesis and long-term potentiation compared to young isochronic pairs [22]. Treatment with aged plasma mimics this loss in plasticity, as demonstrated by impaired learning and memory performance and reduced neurogenesis [22]. A study using blood exchange also found that aged blood impairs muscle-related performance and hippocampal neurogenesis [17]. Finally, a recent heterochronic parabiosis study reported that young mice sharing aged blood exhibit reduced chondrocyte proliferation in the cartilaginous tissue of the knee [30].

Several of the aged blood-mediated phenotypes observed in young parabionts can be recapitulated by systemic treatment with proteins elevated in aged blood ( $\mathrm{Ta}$ ble 1), including CCL11 and $\beta$-2-microglobulin (B2M). Young mice treated systemically with recombinant CCL11 or B2M exhibit impaired memory and reduced hippocampal neurogenesis [22,31]. The accumulation of $\mathrm{B} 2 \mathrm{M}$ in aged muscle and brain may be mediated by TGF- $\beta /$ pSMAD3 signaling [32], and its negative effects on the brain may act in part through MHC I signaling molecules [31]. These results raise the possibility of an alternative therapeutic strategy to young blood or plasma approaches that instead focuses on targeting pro-aging 


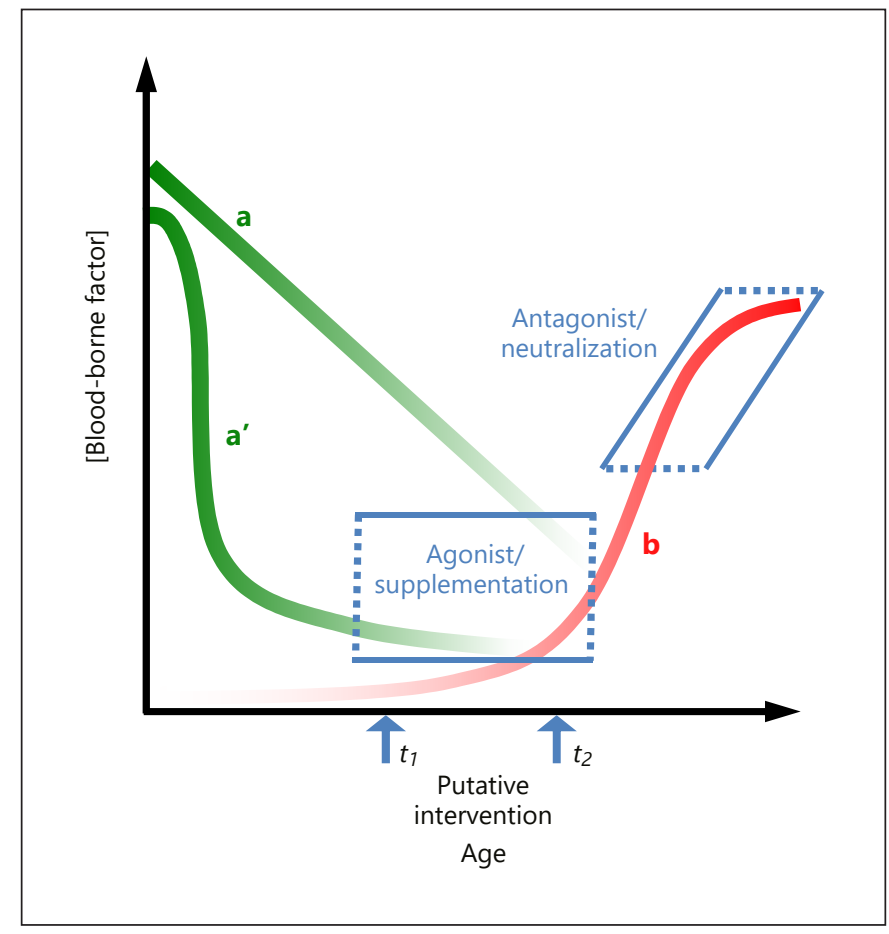

Fig. 1. Hypothetical age-dependent changes in blood-borne factor concentration. Curves in green depict hypothetical concentration changes in youth-associated blood-borne factors that may decline quickly from birth (a') or more gradually over the course of aging (a). The red curve depicts a hypothetical pro-aging factor " $b$ " that accumulates rapidly with advancing age. Blue arrows indicate putative points for therapeutic intervention that may depend on the disease or process being targeted. Possible interventions include approaches targeting the loss of youth-associated activity, either by providing agonists or supplementation with the youth-associated factor, or they may target age-related accumulation of pro-aging activity via antagonists or neutralization of the pro-aging factor.

molecules present within the aged circulation. Such approaches may include antibody-mediated neutralization, antagonist approaches, or the targeting of aging-associated master regulators.

A converse approach has focused on proteins enriched in young plasma that decline with advancing age at varying rates along a hypothetical aging spectrum (Fig. 1). GDF11, which was reported to be elevated in young blood, has been reported to improve cardiac hypertrophy [8], muscle regeneration [9], cerebrovascular integrity, and adult neurogenesis [7], though its precise change along the aging spectrum in blood is under active study and may depend on tools used for its measurement [3335]. Additional analytical tools are needed to determine its precise concentration and activity in complex milieux. Oxytocin, the blood hormone associated with social bonding, parturition, and reproduction, is elevated in young blood and is sufficient to improve age-related declines in muscle regeneration, primarily via MAPK/ERK signaling [11]. Systemic administration of growth hormone-releasing hormone (GHRH) ameliorates age-related cognitive decline in both rodents and human subjects $[36,37]$. TIMP2 was recently found to be elevated in young mouse blood and human umbilical cord plasma [10]. Systemic treatment with TIMP2 increases synaptic plasticity and improves learning and memory in aged mice, while its plasma immunodepletion eliminates the learning and memory benefits conferred by cord plasma [10]. Finally, osteocalcin has recently been identified as another critical component of young plasma activity [12]. Systemic osteocalcin treatment improves memory and anxiety-like behavior in aged mice, acting in part through the orphan receptor GPR158 [12]. Together, these results suggest that multiple factors play distinct roles in mediating the effects of young blood within specific organs (Table 1). Further study is needed to identify whether these factors converge on common pathways to broadly influence tissue rejuvenation.

\section{Conceptual and Practical Challenges to the Realization of Blood-Based Therapies}

To combat the uniquely complex challenges presented by age-associated diseases, innovative strategies are needed that can target the interconnected physiology among organ systems. The body of work identifying signals in the systemic environment that either accelerate or ameliorate aging in many tissues takes advantage of this complex physiology. Especially in the case of certain central nervous system disorders where the blood-brain barrier often thwarts attempts to reach targets within brain parenchyma, blood-based therapies offer unique advantages. Though blood products have been safely used in a medical setting to treat a variety of conditions for many years, their use for the treatment of aging-related conditions is not without challenges and requires thoughtful consideration before rapid translation.

One challenge to translation is the inherent complexity of blood products. Aside from collection, quality control, supply, and lot heterogeneity logistics, the potential for simultaneously transferring factors that counteract or limit rejuvenating potential of more potent, purified factors is likely. Given the association of rejuvenating factors with growth and developmental processes, the possibility also exists for transferring factors that confer unwanted 
side effects that potentially raise the risk of cancer or other conditions, especially in the setting of a sustained treatment course. Nearly all our current understanding related to the link between the systemic environment and aging has been gleaned from animal studies, making it unclear whether the effects cross species barriers. One approach to circumvent aspects of this issue has been the development of aged immunodeficient mouse models to directly test the activity of human plasma and its fractions [10], provided that factors identified in this way are then assayed in normal mice to determine whether effects observed depend on normal immune function. Consideration of mouse and human differences may be important given the focus on neurogenesis-related phenotypes in the brain $[7,22,31]$ (see [38] for review), especially as the existence of appreciable adult neurogenesis in the human brain and whether there is age-related decline is actively contested [39-42]. Studies in higher organisms (e.g., nonhuman primates) may ultimately be needed to guide development of specific protein factors for anti-aging applications. These risks may be greatly mitigated by the use of refined fractions tested preclinically and following rigorous assessments in a placebo-controlled, double-blind and randomized trial design. Approaches that target more than one biological process and multiple tissues, possibly through the identification of common pathways, may be advantageous to limit the systemic effects of aging, though design considerations may need to cope with conflicting influence of factors on different tissues that may complicate rejuvenation-related treatment. In certain cases, blood-based therapies risk oversimplifying complex age-related diseases unless they can be tailored to distinct disease phases along the aging spectrum. For example, distinct approaches may be needed to either tar- get early-stage lesions in $\mathrm{AD}$ or the late-stage synaptic dysfunction observed later in the course of AD (Fig. 1).

Finally, as different blood-based therapies are considered and designed, various ethical challenges should inform their development. Blood plasma is not an unlimited commodity, and access to the resource may be divided disproportionately within different health systems. Those with means may potentially benefit from a market that preys on those who are economically disadvantaged, setting up improper incentives to evaluate efficacy or generalizability. The ease with which blood and plasma can be transferred to another individual also raises the specter of exploitation in unregulated markets where safety to both subjects and donors would be in jeopardy. The execution of rigorous, peer-reviewed preclinical research followed by standardized clinical trials is a sensible approach to mitigating, while not eliminating, these potential abuses of emerging blood-based therapies. How these approaches are tested, designed, and implemented will play a large part in determining whether blood-based therapy grows beyond a quixotic concept into life-saving medicine.

\section{Acknowledgements}

Funding from the NIA/NIH (R00AG051711), Katz and Martin Friedman Brain Institute Award, and from the BrightFocus Foundation is gratefully acknowledged.

\section{Disclosure Statement}

J.M.C. holds equity in the form of stock in Alkahest, Inc., to whom the use of plasma (PCT/US2014/068897) and TIMP2 (PCT/ US2016/036032) in aging and disease has been licensed.

\section{References}

1 Kennedy BK, Berger SL, Brunet A, Campisi J, Cuervo AM, Epel ES, Franceschi C, Lithgow GJ, Morimoto RI, Pessin JE, Rando TA, Richardson A, Schadt EE, Wyss-Coray T, Sierra F: Geroscience: linking aging to chronic disease. Cell 2014;159:709-713.

2 de Magalhaes JP, Stevens M, Thornton D: The business of anti-aging science. Trends Biotechnol 2017;35:1062-1073.

3 Mattison JA, Colman RJ, Beasley TM, Allison $\mathrm{DB}$, Kemnitz JW, Roth GS, Ingram DK, Weindruch R, de Cabo R, Anderson RM: Caloric restriction improves health and survival of rhesus monkeys. Nat Commun 2017;8: 14063.
4 Wei M, Brandhorst S, Shelehchi M, Mirzaei $\mathrm{H}$, Cheng CW, Budniak J, Groshen S, Mack WJ, Guen E, Di Biase S, Cohen P, Morgan TE, Dorff T, Hong K, Michalsen A, Laviano A, Longo VD: Fasting-mimicking diet and markers/risk factors for aging, diabetes, cancer, and cardiovascular disease. Sci Transl Med 2017, DOI: 10.1126/scitranslmed. aai8700.

5 Castellano JM, Kirby ED, Wyss-Coray T: Blood-borne revitalization of the aged brain. JAMA Neurol 2015;72:1191-1194.

6 Wyss-Coray T: Ageing, neurodegeneration and brain rejuvenation. Nature 2016;539: 180-186.
7 Katsimpardi L, Litterman NK, Schein PA, Miller CM, Loffredo FS, Wojtkiewicz GR, Chen JW, Lee RT, Wagers AJ, Rubin LL: Vascular and neurogenic rejuvenation of the aging mouse brain by young systemic factors. Science 2014;344:630-634.

8 Loffredo FS, Steinhauser ML, Jay SM, Gannon J, Pancoast JR, Yalamanchi P, Sinha M, Dall'Osso C, Khong D, Shadrach JL, Miller CM, Singer BS, Stewart A, Psychogios N, Gerszten RE, Hartigan AJ, Kim MJ, Serwold T, Wagers AJ, Lee RT: Growth differentiation factor 11 is a circulating factor that reverses age-related cardiac hypertrophy. Cell 2013; 153:828-839. 
9 Sinha M, Jang YC, Oh J, Khong D, Wu EY, Manohar R, Miller C, Regalado SG, Loffredo FS, Pancoast JR, Hirshman MF, Lebowitz J, Shadrach JL, Cerletti M, Kim MJ, Serwold T, Goodyear LJ, Rosner B, Lee RT, Wagers AJ: Restoring systemic GDF11 levels reverses age-related dysfunction in mouse skeletal muscle. Science 2014;344:649-652.

10 Castellano JM, Mosher KI, Abbey RJ, McBride AA, James ML, Berdnik D, Shen JC, Zou B, Xie XS, Tingle M, Hinkson IV, Angst MS, Wyss-Coray T: Human umbilical cord plasma proteins revitalize hippocampal function in aged mice. Nature 2017;544:488-492.

11 Elabd C, Cousin W, Upadhyayula P, Chen RY, Chooljian MS, Li J, Kung S, Jiang KP, Conboy IM: Oxytocin is an age-specific circulating hormone that is necessary for muscle maintenance and regeneration. Nat Commun 2014;5:4082.

12 Khrimian L, Obri A, Ramos-Brossier M, Rousseaud A, Moriceau S, Nicot AS, Mera P, Kosmidis S, Karnavas T, Saudou F, Gao XB, Oury F, Kandel E, Karsenty G: Gpr158 mediates osteocalcin's regulation of cognition. J Exp Med 2017;214:2859-2873.

13 Ludwig FC, Elashoff RM: Mortality in syngeneic rat parabionts of different chronological age. Trans NY Acad Sci 1972;34:582-587.

14 McCay CM, Pope F, Lunsford W, Sperling G, Sambhavaphol P: Parabiosis between old and young rats. Gerontologia 1957;1:7-17.

15 Conboy IM, Conboy MJ, Wagers AJ, Girma ER, Weissman IL, Rando TA: Rejuvenation of aged progenitor cells by exposure to a young systemic environment. Nature 2005;433:760764.

16 Brack AS, Conboy MJ, Roy S, Lee M, Kuo CJ, Keller C, Rando TA: Increased Wnt signaling during aging alters muscle stem cell fate and increases fibrosis. Science 2007;317:807-810.

17 Rebo J, Mehdipour M, Gathwala R, Causey K, Liu Y, Conboy MJ, Conboy IM: A single heterochronic blood exchange reveals rapid inhibition of multiple tissues by old blood. Nat Commun 2016;7:13363.

18 Castellano JM, Palner M, Li SB, Freeman GM Jr, Nguyen A, Shen B, Stan T, Mosher KI, Chin FT, de Lecea L, Luo J, Wyss-Coray T: In vivo assessment of behavioral recovery and circulatory exchange in the peritoneal parabiosis model. Sci Rep 2016;6:29015.

19 Salpeter SJ, Khalaileh A, Weinberg-Corem N, Ziv O, Glaser B, Dor Y: Systemic regulation of the age-related decline of pancreatic beta-cell replication. Diabetes 2013;62:2843-2848.

20 Huang Q, Ning Y, Liu D, Zhang Y, Li D, Zhang Y, Yin Z, Fu B, Cai G, Sun X, Chen X: A young blood environment decreases aging of senile mice kidneys. J Gerontol A Biol Sci Med Sci 2018;73:421-428.

21 Baht GS, Silkstone D, Vi L, Nadesan P, Amani Y, Whetstone H, Wei Q, Alman BA: Exposure to a youthful circulation rejuvenates bone repair through modulation of beta-catenin. Nat Commun 2015;6:7131.
22 Villeda SA, Luo J, Mosher KI, Zou B, Britschgi M, Bieri G, Stan TM, Fainberg N, Ding Z, Eggel A, Lucin KM, Czirr E, Park JS, Couillard-Despres S, Aigner L, Li G, Peskind ER, Kaye JA, Quinn JF, Galasko DR, Xie XS, Rando TA, Wyss-Coray T: The ageing systemic milieu negatively regulates neurogenesis and cognitive function. Nature 2011;477:90-94.

23 Villeda SA, Plambeck KE, Middeldorp J, Castellano JM, Mosher KI, Luo J, Smith LK, Bieri G, Lin K, Berdnik D, Wabl R, Udeochu J, Wheatley EG, Zou B, Simmons DA, Xie XS, Longo FM, Wyss-Coray T: Young blood reverses age-related impairments in cognitive function and synaptic plasticity in mice. Nat Med 2014;20:659-663.

24 Ruckh JM, Zhao JW, Shadrach JL, van Wijngaarden P, Rao TN, Wagers AJ, Franklin RJ: Rejuvenation of regeneration in the aging central nervous system. Cell Stem Cell 2012; 10:96-103.

25 Liu A, Guo E, Yang J, Yang Y, Liu S, Jiang X, Hu Q, Dirsch O, Dahmen U, Zhang C, Gewirtz DA, Fang H: Young plasma reverses age-dependent alterations in hepatic function through the restoration of autophagy. Aging Cell 2018;17.

26 Middeldorp J, Lehallier B, Villeda SA, Miedema SS, Evans E, Czirr E, Zhang H, Luo J, Stan T, Mosher KI, Masliah E, Wyss-Coray T: Preclinical assessment of young blood plasma for Alzheimer disease. JAMA Neurol 2016;73: $1325-1333$

27 Xiang Y, Bu XL, Liu YH, Zhu C, Shen LL, Jiao SS, Zhu XY, Giunta B, Tan J, Song WH, Zhou HD, Zhou XF, Wang YJ: Physiological amyloid-beta clearance in the periphery and its therapeutic potential for Alzheimer's disease. Acta Neuropathol 2015;130:487-499.

28 Habib A, Hou H, Mori T, Tian J, Zeng J, Fan S, Giunta B, Sanberg PR, Sawmiller D, Tan J: Human umbilical cord blood serum-derived alpha-secretase: functional testing in Alzheimer's disease mouse models. Cell Transplant 2018;27:438-455.

29 Kaiser J: Blood from young people does little to reverse Alzheimer's in first test. Science 2017, DOI: $10.1126 /$ science.aar3723.

30 Li L, Wei X, Geng X, Duan Z, Wang X, Li P, Wang C, Wei L: Impairment of chondrocyte proliferation after exposure of young murine cartilage to an aged systemic environment in a heterochronic parabiosis model. Swiss Med Wkly 2018;148:w14607.

31 Smith LK, He Y, Park JS, Bieri G, Snethlage CE, Lin K, Gontier G, Wabl R, Plambeck KE, Udeochu J, Wheatley EG, Bouchard J, Eggel A, Narasimha R, Grant JL, Luo J, Wyss-Coray T, Villeda SA: beta2-microglobulin is a systemic pro-aging factor that impairs cognitive function and neurogenesis. Nat Med 2015;21:932-937.

32 Yousef H, Conboy MJ, Morgenthaler A, Schlesinger C, Bugaj L, Paliwal P, Greer C, Conboy IM, Schaffer D: Systemic attenuation of the TGF-beta pathway by a single drug simultaneously rejuvenates hippocampal neurogenesis and myogenesis in the same old mammal. Oncotarget 2015;6:11959-11978.
33 Egerman MA, Cadena SM, Gilbert JA, Meyer A, Nelson HN, Swalley SE, Mallozzi C, Jacobi C, Jennings LL, Clay I, Laurent G, Ma S, Brachat S, Lach-Trifilieff E, Shavlakadze T, Trendelenburg AU, Brack AS, Glass DJ: GDF11 increases with age and inhibits skeletal muscle regeneration. Cell Metab 2015;22:164-174.

34 Harper SC, Brack A, MacDonnell S, Franti M, Olwin BB, Bailey BA, Rudnicki MA, Houser SR: Is growth differentiation factor 11 a realistic therapeutic for aging-dependent muscle defects? Circ Res 2016;118:1143-1150; discussion 1150.

35 Walker RG, Poggioli T, Katsimpardi L, Buchanan SM, Oh J, Wattrus S, Heidecker B, Fong YW, Rubin LL, Ganz P, Thompson TB, Wagers AJ, Lee RT: Biochemistry and biology of GDF11 and myostatin: similarities, differences, and questions for future investigation. Circ Res 2016;118:1125-1141; discussion 1142.

36 Baker LD, Barsness SM, Borson S, Merriam GR, Friedman SD, Craft S, Vitiello MV: Effects of growth hormone-releasing hormone on cognitive function in adults with mild cognitive impairment and healthy older adults: results of a controlled trial. Arch Neurol 2012. 69:1420-1429.

37 Thornton PL, Ingram RL, Sonntag WE: Chronic (D-Ala2)-growth hormone-releasing hormone administration attenuates agerelated deficits in spatial memory. J Gerontol A Biol Sci Med Sci 2000;55:B106-B112.

38 Smith LK, White CW 3rd, Villeda SA: The systemic environment: at the interface of aging and adult neurogenesis. Cell Tissue Res 2018;371:105-113.

39 Boldrini M, Fulmore CA, Tartt AN, Simeon LR, Pavlova I, Poposka V, Rosoklija GB, Stankov A, Arango V, Dwork AJ, Hen R, Mann JJ: Human hippocampal neurogenesis persists throughout aging. Cell Stem Cell 2018;22:589-599.e585.

40 Dennis CV, Suh LS, Rodriguez ML, Kril JJ, Sutherland GT: Human adult neurogenesis across the ages: an immunohistochemical study. Neuropathol Appl Neurobiol 2016;42: 621-638.

41 Sorrells SF, Paredes MF, Cebrian-Silla A, Sandoval K, Qi D, Kelley KW, James D, Mayer S, Chang J, Auguste KI, Chang EF, Gutierrez AJ, Kriegstein AR, Mathern GW, Oldham MC, Huang EJ, Garcia-Verdugo JM, Yang Z, Alvarez-Buylla A: Human hippocampal neurogenesis drops sharply in children to undetectable levels in adults. Nature 2018;555:377381.

42 Spalding KL, Bergmann O, Alkass K, Bernard S, Salehpour M, Huttner HB, Bostrom E, Westerlund I, Vial C, Buchholz BA, Possnert G, Mash DC, Druid H, Frisen J: Dynamics of hippocampal neurogenesis in adult humans. Cell 2013;153:1219-1227. 